\title{
PEMBEKALAN SOFT-SKILL MENGGUNAKAN MEDIA KOMPUTER BAGI TIM PENGERAK DAN KELOMPOK PKK DI KELURAHAN BULU LOR
}

\author{
Soft-Skill Training Using The Computer Media For The Activator Team and Group of \\ Program Kesejahteraan Keluarga (PKK) in Kelurahan Bulu Lor
}

\author{
Aripin $^{1}$, Cinantya Paramita ${ }^{2}$, Muljono ${ }^{3}$ \\ 1,2,3Universitas Dian Nuswantoro; Jl. Imam Bonjol 207 Semarang, (024)-3517261 \\ ${ }^{1,2,3}$ Program Teknik Informatika, Fakultas Ilmu Komputer - UDINUS, Semarang \\ e-mail: ${ }^{1}$ arifin@dsn.dinus.ac.id, ${ }^{2}$ cinantya.paramita@dsn.dinus.ac.id, ${ }^{3}$ muljono@dsn.dinus.ac.id
}

\begin{abstract}
Abstrak
Perkembangan teknologi komputer semakin canggih dan sangat populer diberbagai kalangan masyarakat. Tim Pengerak dan Kelompok PKK di Keluruhan Bulu Lor sebagai salah satu organisasi yang ada dilingkungan Kelurahan Bulu Lor mempunyai program untuk meningkatkan pemberdayaan wanita dalam kehidupan sehari-hari maupun kegiatan kemasyarakatan lainnya. Program ini diharapkan dapat meningkatkan peran dan sekaligus memberdayakan kinerja Tim Penggerak dan kelompok PKK tersebut secara inovatif. Beberapa tahapan kegiatan yang diusulkan untuk mencapai tujuan program tersebut terdiri dari pelatihan soft-skill anggota Tim Penggerak dan kelompok PKK, pendampingan pemecahan masalah dilapangan dan evaluasi kegiatan agar pelaksanaan program menjadi lebih baik. Kegiatan pelatihan terdiri dari pelatihan untuk meningkatkan pengetahuan dan keterampilan penggunaan teknologi komputer untuk mendukung proses administrasi di Kelurahan Bulu Lor dan pelatihan untuk meningkatkan keterampilan program penyuluhan agar masyarakat ikut termotivasi untuk mendukung seluruh program / kegiatan Kelurahan Bulu Lor. Hasil dari kegiatan pembekalan soft-skill ini berdampak sangat baik bagi peningkatan kinerja Tim Penggerak dan kelompok PKK serta peningkatan partisipasi masyarakat terhadap seluruh program / kegiatan di Keluruhan Bulu Lor. Ini dapat dilihat dari hasil evaluasi partisipasi masyarakat yang mencapai 90\% dari seluruh program / kegiatan di Keluruhan Bulu Lor yang didukung sepenuhnya oleh partisipasi masyarakat.
\end{abstract}

Kata kunci-Keterampilan penyuluhan, Pembekalan Soft-Skill, Teknologi Komputer, Tim Penggerak dan Kelompok PKK di Kelurahan Bulu Lor

\begin{abstract}
The development of computer technology increasingly sophisticated and very popular in various circles of society. The activator and group of PKK in Kelurahan Bulu Lor as one of the social organization has a program to improve women empowerment in daily life and in social activities. This program aims to enhance the role and at the same time empower the performance of the activator and group of PKK innovatively. Several steps of the proposed activities to achieve the program's objectives consist of soft-skill training for The activator and group of PKK members, accompaniment of problem solving and periodic and continuous evaluation in order to make the program better. The training activities consisted of training to increase knowledge and skills in the use of computer technology to support administrative processes in Kelurahan Bulu Lor and training to improve skills in extension activities of various programs / activities so that people participate motivated to support all the programs /
\end{abstract}


activities. The results of soft-skill training activities have an excellent impact on improving the performance of The activator and group of PKK and increasing society participation in all programs / activities in Keluruhan Bulu Lor. This can be seen from the evaluation of society participation that reaches $90 \%$ of all programs / activities in Keluruhan Bulu Lor which is fully supported by society.

Keywords - extension skills, soft-skill training, computer technology, The activator and group of PKK in Kelurahan Bulu Lor

\section{PENDAHULUAN}

Perkembangan teknologi komputer yang sangat cepat dan semakin modern telah mempengaruhi semua aspek kehidupan. Pada era saat ini tidak ada aspek kehidupan yang tidak terpengaruh oleh teknologi komputer [1]. Oleh karena itu, setiap orang harus dapat menyesuaikan perkembangan teknogi komputer tersebut agar tidak tertinggal. Salah satu bidang yang juga terpengaruh oleh perkembangan teknologi komputer adalah bidang administrasi pelayanan masyarakat baik lingkup yang lebih luas maupun lingkup yang cukup kecil misalnya wilayah kelurahan. Program / kegiatan yang ada di kelurahan seperti pemberdayaan wanita, penyuluhan program / kegiatan pembangunan, pelayanan administrasi dan aktivitas kehidupan sehari-hari sangat memerlukan penggunaan teknologi komputer untuk mempermudah dan mendukung kegiatan-kegiatan tersebut.

Berbagai organisasi yang ada dilingkup kelurahan seperti Tim Penggerak dan kelompok PKK sangat membantu pihak kelurahan dalam mendukung terlaksananya program-program yang ada dikelurahan. Tim Penggerak dan kelompok PKK dapat berperan aktif dalam kegiatan penyuluhan program-program untuk masyarakat maupun meningkatkan hubungan kemasyarakatan dalam kehidupan sehari-hari. Selain itu, Tim Penggerak dan kelompok PKK terbentuk di masyarakat untuk berperan dalam meningkatkan pemberdayaan wanita. Tim Penggerak dan kelompok PKK terbentuk dari setruktur organisasi yang paling bawah yaitu Dasa Wisma (Dawis) Rukun Tetangga (RT), Dawis Rukun Warga (RW), Dasa Wisma Kelurahan, Dawis Kecamatan, Dawis Kabupaten/Kota dan Dawis Propinsi.

Seiring perkembangan jaman, peran Tim Penggerak dan kelompok PKK semakin bertambah penting didalam kehidupan bermasyarakat. Tugas Tim Penggerak dan kelompok PKK tidak lagi hanya sebatas hal-hal yang berhubungan dengan keluarga saja tapi sudah mulai merambah kepada kegiatan-kegiatan pendataan kependudukan, penanganan lingkungan hidup, masalah kesehatan, kegiatan sosial dan masih banyak lagi. Perkembangan teknologi komputer memberikan kemudahan pada semua pekerjaan tersebut. Masalah yang sedang dihapai oleh Tim Penggerak dan kelompok PKK di Kelurahan Bulu Lor adalah minimnya keterampilan menggunakan teknologi komputer dan terbatasnya kemampuan anggota Tim Penggerak dan kelompok PKK dalam memberikan penyuluhan kepada masyarakat luas. Dengan adanya masalah-masalah ini, banyak tugas-tugas yang berkaitan dengan administrasi tidak dapat diselesaikan tepat waktu dan kualitas hasil pekerjaan yang tidak rapi. Dampak lain dari adanya masalah-masalah tersebut adalah partisipasi masyarakat terhadap program-program kelurahan sangat rendah sehingga banyak program kelurahan yang tidak berjalan sebagaimana mestinya.

Kegiatan pengabdian masyarakat yang diselenggarakan ini merupakan salah satu cara untuk membantu pemerintah Kelurahan Bulu Lor untuk mengurangi kendala-kendala di atas. Kegiatan pengabdian masyarakat ditujukan untuk memberi pengetahuan dan keterampilan mengenai penggunaan teknologi komputer dan kemampuan Tim Penggerak dan kelompok PKK dalam memberikan penyuluhan kepada masyarakat luas sehingga pertisipasi masyarakat terhadap program-program kelurahan meningkat. Kegiatan pengabdian masyarakat ini terbadi menjadi 3 sub kegiatan, yaitu pelatihan soft-skill penggunaan teknologi komputer dan 
keterampilan dalam memberikan penyuluhan kepada masyarakat, pendampingan pemecahan masalah dilapangan, dan evaluasi dampak kegiatan pengabdian masyarakat. Pada sub kegiatan evaluasi, adanya pengkajian dampak pelatihan penggunakan teknologi komputer terhadap kinerja Tim Penggerak dan kelompok PKK dan pengkajian dampak pelatihan keterampilan dalam memberikan penyuluhan terhadap tingkat partisipasi masyarakat terhadap programprogram yang ada dilingkup kelurahan.

Berdasarkan analisis situasi dan permasalahan-permasalahan yang dihadapi oleh Tim Penggerak dan kelompok PKK di Kelurahan Bulu Lor, maka rumusan permasalahan dalam kegiatan pengabdian masyarakat ini adalah minimnya pelatihan mengenai pengetahuan dan keterampilan penggunaan teknologi Komputer yang sangat penting bagi Tim Penggerak dan kelompok PKK dan keterbatasan keterampilan Tim Penggerak dan kelompok PKK dalam memberikan penyuluhan kepada masyarakat.

\section{METODE PENELITIAN}

Metode yang diusulkan untuk membantu menyelesaikan permasalahan-permasalahan di atas terdiri dari beberapa tahapan penelitian. Tahapan-tahapan penelitian tersebut secara garis besar dapat dilihat seperti Gambar 1. Tahap pertama dari metode yang diusulkan ini identifikasi masalah. Untuk mengidentifikasi masalah-masalah yang sesungguhnya sedang dihadapi, maka dilakukan analisis situasi, analisis kinerja administrasi Tim Penggerak dan kelompok PKK serta analisis partisipasi masyarakat terhadap program-program yang digulirkan oleh kelurahan. Selanjutnya, diusulkan kegiatan untuk menyelesaikan masalah-masalah tersebut dengan menyelenggarakan dua kegiatan pelatihan yaitu pelatihan keterampilan penggunaan teknologi komputer dan keterampilan dalam memberikan penyuluhan. Kedua kegiatan pelatihan ini dinamakan dengan kegiatan pembekalan soft-skill. Agar pembekalan soft-skill dapat berkelanjutan, maka kegiatan selanjutnya yang dilakukan adalah pendampingan dilapangan. Kegiatan-kegiatan dilapangan oleh Tim Penggerak dan kelompok PKK didampingi oleh beberapa orang dari tim pengabdian masyarakat yang memberikan bantuan konsultasi dan memastikan bahwa materi-materi pelatihan yang telah diberikan memberikan manfaat bagi Tim Penggerak dan kelompok PKK dalam menjalankan tugasnya. Tahap dari metode yang diusulkan ini adalah evaluasi penerapan keseluruhan metode pada Tim Penggerak dan kelompok PKK. Evaluasi ini dimaksudkan untuk memperoleh informasi dampak dari kegiatan pelatihan yang telah dilakukan. Dari Hasil evaluasi juga dapat digunakan sebagai dasar untuk melakukan perbaikan-perbaikan untuk kegiatan yang akan datang.

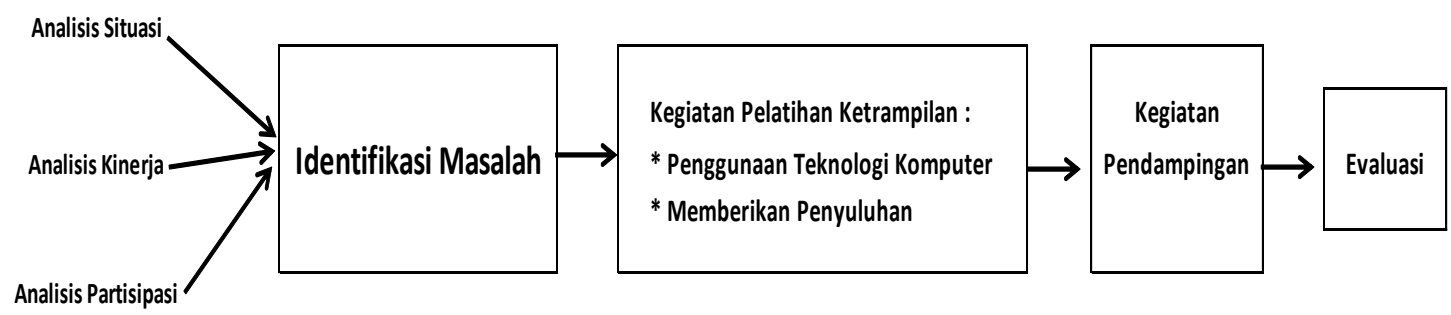

Gambar 1. Metode Yang Diusulkan Untuk Menyelesaikan Masalah

Uaraian lebih rinci dari masing-masing tahap penelitian di atas adalah sebagai berikut:

\subsection{Identifikasi Masalah}

Identifikasi masalah merupakan langkah awal yang sangat penting sehingga solusi pemecahan masalah dapat menyelesaikan masalah dengan tepat. Untuk memperoleh gambaran masalah dilakukan beberapa analisis yaitu analisis situasi, analisis kinerja dan analisis 
partisipasi masyarakat terhadap program-program yang digulirkan oleh Kelurahan Bulu Lor. Analisis situasi dilakukan dengan mengamati peran Tim Penggerak dan kelompok PKK di masyarakat dan perannya dalam upaya untuk meningkatkan pemberdayaan wanita dalam kehidupan sehari-hari. Pengamatan dilakukan pada kelompok Dasa Wsima (Dawis) mulai dari Dawis tingkat RT, tingkat RW dan Dawis tingkat Kelurahan Bulu Lor. Analisis kinerja merupakan analisis terhadap kinerja administrasi Tim Penggerak dan kelompok PKK dalam melaksanakan tugas pelayanan kepada masyarakat, penyusunan laporan untuk pimpinan Kelurahan Bulu Lor, dan tugas kemitraan dengan organisasi lain diluar Kelurahan Bulu Lor. Sedangkan analisis partisipasi adalah analisis partisipasi, dukungan dan keterlibatan masyarakat terhadap program-program yang digulirkan Kelurahan Bulu Lor. Analisis partisipasi ini dimaksudkan untuk mengetahui dampak penyuluhan-penyuluhan yang telah dilakukan oleh Tim Penggerak dan kelompok PKK terhadap program-program yang digulirkan oleh Kelurahan Bulu Lor. Apabila partisipasi, dukungan dan keterlibatan masyarakat terhadap program-program Keluharan Bulu Lor menunjukan prosentase yang kurang baik, hal ini berarti bahwa penyuluhan-penyuluhan yang telah dilakukan Tim Penggerak dan kelompok PKK belum memberikan dampak yang baik. Ini dapat disebabkan oleh kurang efektifnya metode penyuluhan yang telah dilakukan sehingga memerlukan perbaikan metode penyuluhan. Data dan fakta yang dapat ditemukan dari kegiatan analisis situasi, analisis kinerja dan analisis partisipasi digunakan sebagai dasar untuk merumuskan identifikasi masalah yang sedang dihadapi.

Identifikasi masalah yang berhasil dirumuskan dalam penelitian ini adalah minimnya pengetahuan dan keterampilan anggota Tim Penggerak dan kelompok PKK di Kelurahan Bulu Lor terhadap penggunaan teknologi komputer dan kemampuan dalam memberikan penyuluhan program-program Kelurahan Bulu Lor.

\subsection{Pelaksanaan Pelatihan}

Dua masalah utama yang telah dirumuskan dari hasil identifikasi masalah dari tahap sebelumnya digunakan sebagai dasar tujuan penyelesaian masalah dari penelitian ini. Solusi pemecahan masalah yang diusulkan adalah program pelatihan soft-skill untuk anggota Tim Penggerak dan kelompok PKK di Kelurahan Bulu Lor yang terdiri dari pelatihan keterampilan penggunaan teknologi komputer dan pelatihan keterampilan untuk memberikan penyuluhan.

Pelatihan keterampilan penggunaan teknologi komputer yang diselenggarakan untuk anggota Tim Penggerak dan kelompok PKK di Kelurahan Bulu Lor adalah kemampuan mengoperasikan beberapa paket software aplikasi perkantoran seperti Microsoft Word, Microsoft Excel, Microsoft Pomerpoint dan teknologi Internet. Pelatihan keterampilan pengoperasian perangkat lunak Microsoft Word ditujukan untuk memberikan bekal keterampilan kepada anggota Tim Penggerak dan kelompok PKK mengenai kemampuan surat menyurat dan pengolahan naskah. Pelatihan materi ini akan membantu anggota Tim Penggerak dan kelompok PKK dalam melaksanakan tugas-tugas administrasi. Pelatihan perangkat lunak Microsoft Excel ditujukan untuk memberikan keterampilan anggoata Tim Penggerak dan kelompok PKK mengenai kemampuan pembuatan tabel-tabel dan pembuatan laporan untuk pimpinan di Kelurahan Bulu Lor. Pelatihan perangkat lunak Microsoft Powerpoint ditujukan untuk memberikan keterampilan pembuatan dan penyusunan bahan-bahan presentasi yang menarik. Dengan materi ini anggota Tim Penggerak dan kelompok PKK mempunyai kemampuan untuk menyusun bahan presentasi. Sedangkan pelatihan teknologi internet ditujukan agar anggota Tim Penggerak dan kelompok PKK dapat menggunakan internet untuk pencarian informasi, surat menyurat elektronik, dan pembuatan blog. Materi ini sangat penting bagi anggota Tim Penggerak dan kelompok PKK agar kegiatan-kegiatan Tim Penggerak dan kelompok PKK di Kelurahan Bulu Lor dapat disosialisasikan dengan cepat dan mudah. Gambar 2 menampilkan sebagian peserta pelatihan dan narasumber pelatihan. 


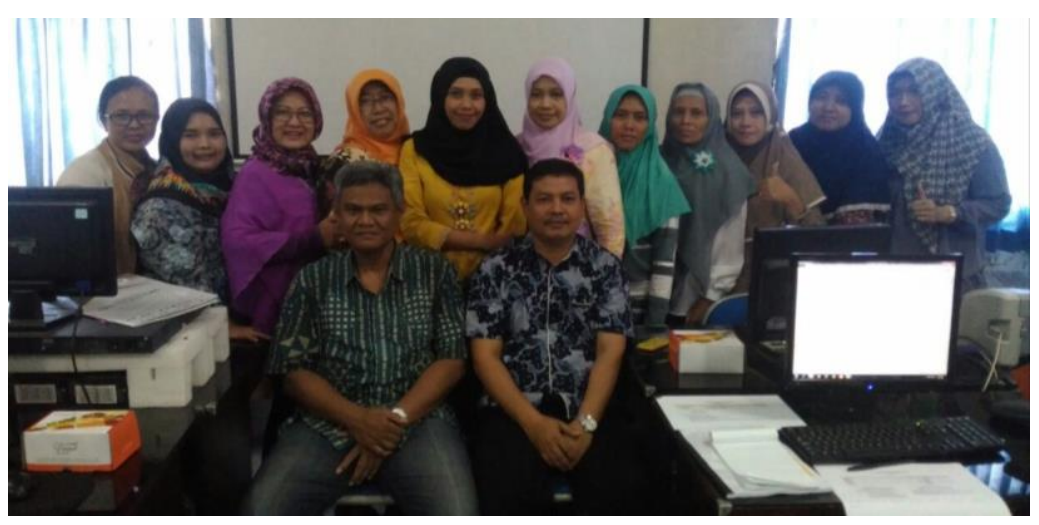

Gambar 2. Sebagian Peserta Pelatihan dan Narasumber Pelatihan

Pelatihan keterampilan penyuluhan terhadap program-program Kelurahan Bulu Lor diisi dengan materi cara mengkomunikasikan pesan kepada orang lain agar efektif. Seorang penyuluh berfungsi sebagai komunikator bertugas menyampaikan pesan kepada audien dengan tujuan mengubah perilaku masyarakat terhadap program-program Kelurahan Bulu Lor. Keterampilan berkomunikasi merupakan salah satu faktor yang harus dimiliki oleh seorang penyuluh $[2,3]$. Dalam komunikasi verbal diperlukan beberapa keterampilan seperti keterampilan menulis, berbicara, mendengarkan dan berpikir secara logis [4]. Materi-materi yang disampaikan dalam pelatihan ini mencakup materi-materi untuk meningkatkan kemampuan seorang penyuluh yang meliputi kemampuan menguasai materi, kemampuan berkomunikasi dan kemampuan mengembangkan mitra. Secara garis besar, metode yang diterapkan dalam kegiatan pelatihan tersaji pada Gambar 3. Metode peningkatan kemampuan penyuluh didasarkan pada hasil analisis antara kemampuan penyuluh saat dengan kemampuan penyuluh yang diharapkan (ideal) [5]. Dari hasil analisis adalah gap yang digunakan sebagai dasar untuk tujuan pelatihan yaitu meningkatkan kemampuan penyuluh saat ini agar gap-nya tidak terlalu besar (kemampuan penyuluh saat ini sudah sesuai dengan kemampuan penyuluh yang diharapkan). Faktor internal dan faktor eksternal menjadi variabel acuan untuk meningkatkan kapasitas penyuluh.

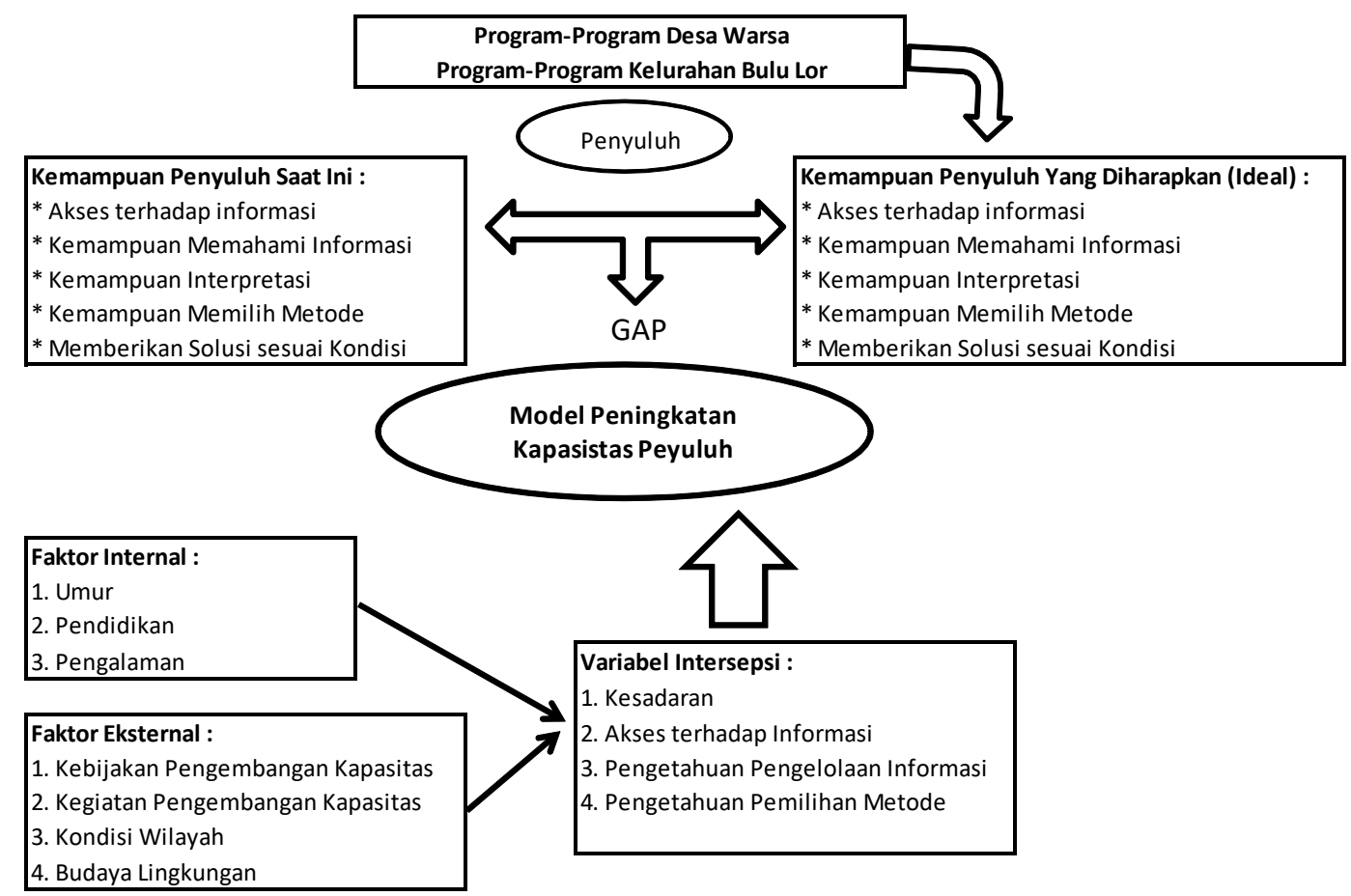

Gambar 3. Metode Untuk Meningkatkan Kemampuan Penyuluh 


\subsection{Kegiatan Pendampingan}

Untuk menjamin pelaksaan program pelatihan di Kelurahan Bulu Lor, maka perlu adanya kegiatan pendampingan pada tiap-tiap program Tim Penggerak dan kelompok PKK. Mekanisme pendampingan adalah dengan kegiatan konsultasi dari tim peneliti dengan Tim Penggerak dan kelompok PKK yang dilaksanakan secara periodik yaitu seminggu sekali setiap hari jumat. Kegiatan konsultasi ini dilaksanalan apabila Tim Penggerak dan kelompok PKK menemukan permasalahan mengenai penggunaan teknologi komputer dan kendala teknis dalam program penyuluhan. Tim peneliti akan memberikan rekomendasai pemecahan masalah berkaitan dengan permasalahan-permasalahan tersebut.

\subsection{Evaluasi Kegiatan}

Evaluasi kegiatan dimaksudkan untuk mengevaluasi hasil pelaksanaan kegiatan pelatihan terhadap pelaksanaan program-program Tim Penggerak dan kelompok PKK di Kelurahan Bulu lor. Evaluasi kegiatan dilaksanakan setelah kegiatan pelatihan selesai dilaksanakan dan implementasi pada kegiatan dan pelaksanaan program-program Tim Penggerak dan kelompok PKK selama 3 bulan. Bagi tim peneliti, hasil evaluasi kegiatan digunakan sebagai dasar untuk melakukan perbaikan-perbaikan pada program pelatihan yang akan jalankan di objek yang berbeda. Sedangkan bagi Tim Penggerak dan kelompok PKK di Kelurahan Bulu Lor, evaluasi kegiatan dapat digunakan untuk perbaikan pelayanan dan pelaksanaan program-program di Kelurahan Bulu Lor.

\section{HASIL DAN PEMBAHASAN}

Kegiatan pembekalan soft-skill bagi Tim Penggerak dan Kelompok PKK di Kelurahan Bulu Lor telah dilaksanakan mulai tanggal 8 sampai dengan 12 Januari 2018. Pelaksanaan kegiatan dilaksanakan di Laboratorium Komputer (Lab. D.2.B) Gedung D Kampus Universitas Dian Nuswantoro Jalan Nakula 1 Semarang. Rincian jadwal pelaksanaan kegiatan ini dapat dilihat seperti Tabel 1.

Setelah kegiatan pelatihan dilaksanakan, tahap kegiatan selanjutnya adalah kegiatan pendampingan bagi Tim Penggerak dan Kelompok PKK RT-RW dan Dasa Warsa Kelurahan Bulu Lor selama 3 bulan. Selama kegiatan pendampingan tim penelitia memberikan bantuan solusi pemecahan masalah-masalah yang dihadapi oleh Tim Penggerak dan Kelompok PKK. Seminggu sekali tim peneliti melayani kegiatan konsultasi dengan Tim Penggerak dan Kelompok PKK berkaitan dengan kesulitan teknik yang dihadapi. Selanjutnya tim peneliti akan memberikan bantuan teknis dan rekomendasi pemecahan masalah-masalah tersebut.

Untuk mengetahui dampak dari kegiatan pembekalan soft-skill ini, kami melakukan pengujian tanggapan dari Tim Penggerak dan Kelompok PKK di Kelurahan Bulu Lor. Setiap anggota Tim Penggerak dan Kelompok PKK diminta mengisi tanggapan dan saran dari hasil pelaksanaan pembekalan soft-skill dan kegiatan pendampingan. Penilaian rata-rata dari tanggapan seluruh anggota Tim Penggerak dan Kelompok PKK dihitung dengan menggunakan metode Mean Opinion Score (MOS). Metode ini akan mengukur rata-rata tanggapan dari seluruh anggota Tim Penggerak dan Kelompok PKK. Setiap anggota akan memberikan penilaian deskriptif dengan 5 kriteria kesesuaian seperti yang terlihat pada Tabel 2. Sedangkan, MOS dapat dihitung dengan menggunakan persamaan (1) [6]. 
Tabel 1. Jadwal Pelaksanaan Kegiatan Pembekalan Soft-Skill

\begin{tabular}{|c|l|l|}
\hline No & Waktu & Kegiatan \\
\hline Hari / Tanggal : Senin, 8 Januari 2018 \\
\hline 1 & $08.00-09.00$ & Pendaftaran Peserta dan Pembukaan \\
\hline 2 & $09.00-12.00$ & Materi Dasar Windows \\
\hline 3 & $13.00-15.00$ & Materi pengenalan komputer dan internet \\
\hline \multicolumn{3}{|l|}{ Hari / Tanggal : Selasa, 9 Januari 2018} \\
\hline 1 & $08.00-10.00$ & Materi Microsoft Word \\
\hline 2 & $10.00-10.30$ & Istirahat \\
\hline 3 & $10.30-12.00$ & Materi Microsoft Word \\
\hline 4 & $13.00-15.00$ & Materi Microsoft Word \\
\hline Hari / Tanggal : Rabu, 10 Januari 2018 \\
\hline 1 & $08.00-10.00$ & Materi Microsoft Excel \\
\hline 2 & $10.00-10.30$ & Istirahat \\
\hline 3 & $10.30-12.00$ & Materi Microsoft Excel \\
\hline 4 & $13.00-15.00$ & Materi Microsoft Excel \\
\hline Hari / Tanggal : Kamis, 11 Januari 2018 \\
\hline 1 & $08.00-10.00$ & Materi Microsoft PowerPoint \\
\hline 2 & $10.00-10.30$ & Istirahat \\
\hline 3 & $10.30-12.00$ & Materi Microsoft PowerPoint \\
\hline 4 & $13.00-15.00$ & Materi Penggunaan Internet dan Blog \\
\hline Hari / Tanggal : Jumat, 12 Januari 2018 \\
\hline 1 & $08.00-10.00$ & Materi Teori dan Praktek Komunikasi \\
\hline 2 & $10.00-10.30$ & Istirahat \\
\hline 3 & $10.30-12.00$ & Materi Metode Penyuluhan \\
\hline 4 & $13.00-15.00$ & Materi Teknik Presentasi \\
\hline
\end{tabular}

TABEL 2. Kriteria Nilai MOS

\begin{tabular}{|l|l|lll|}
\hline $\begin{array}{l}\text { Nilai } \\
\text { MOS }\end{array}$ & Kualitas & Keterangan & \\
\hline 5 & $\begin{array}{l}\text { Sangat } \\
\text { Sesuai }\end{array}$ & $\begin{array}{l}\text { Kegiatan Pelatihan sangat sesuai dengan kebutuhan Tim } \\
\text { Penggerak dan Kelompok PKK }\end{array}$ \\
\hline 4 & Sesuai & $\begin{array}{l}\text { Kegiatan Pelatihan sesuai dengan kebutuhan Tim Penggerak dan } \\
\text { Kelompok PKK }\end{array}$ & $\begin{array}{l}\text { Kegiatan Pelatihan cukup sesuai dengan kebutuhan Tim } \\
\text { Penggerak dan Kelompok PKK }\end{array}$ \\
\hline 2 & $\begin{array}{l}\text { Sidak } \\
\text { Sesuai }\end{array}$ & $\begin{array}{l}\text { Kegiatan Pelatihan tidak sesuai dengan kebutuhan Tim } \\
\text { Penggerak dan Kelompok PKK }\end{array}$ \\
\hline 1 & $\begin{array}{l}\text { Sangat } \\
\text { Tidak } \\
\text { Sesuai }\end{array}$ & $\begin{array}{l}\text { Kegiatan Pelatihan sangat tidak sesuai dengan kebutuhan Tim } \\
\text { Penggerak dan Kelompok PKK }\end{array}$ & \\
\hline
\end{tabular}

$$
M O S=\sum_{i=1}^{n} \frac{x(i) \cdot k}{N}
$$

Dimana $x(i)$ adalah nilai sampel ke $i, k$ adalah jumlah bobot dan $N$ adalah jumlah responden. Hasil penilaian oleh seluruh anggota Tim Penggerak dan Kelompok PKK yang dihitung dengan metode MOS dengan menggunakan persamaan (1) menghasilkan nilai MOS sebesar 4,1067 pada range nilai 1 s.d. 5. Ini menunjukan bahwa tingkat kesesuaian antara Kegiatan Pelatihan dengan kebutuhan Tim Penggerak dan Kelompok PKK adalah sesuai. 
Selain pengujian tanggapan dari seluruh anggota Tim Penggerak dan Kelompok PKK, tim peneliti juga menguji dampak program penyuluhan terhadap partisipasi masyarakat mengenai program-program Kelurahan Bulu lor. Dari hasil investigasi diperoleh informasi bahwa partisipasi masyarakat terhadap program-program Kelurahan Bulu Lor meningkat dari $69 \%$ menjadi $90 \%$. Ini dapat dihitung dari jumlah program yang berjalan karena peran dan partisipasi masyarakat di Kelurahan Bulu lor.

\section{KESIMPULAN}

Keseimpulan yang dapat diambil dari hasil pelaksanaan kegiatan Pembekalan Soft-Skill dengan Media Komputer bagi Tim Penggerak dan Kelompok PKK di Kelurahan Bulu Lor adalah sebagai berikut :

1. Kegiata pembekalan soft-skill yang telah dilaksanakan ini memberikan dampak yang positif terhadap pelaksanaan program-program di Kelurahan Bulu Lor. Dampak dari kegiatan ini adalah partisipasi masyarakat terhadap program-program di Kelurahan Bulu Lor meningkat. Ini dapat dilihat dari jumlah program yang dapat berjalan karena peran dan partisipasi masyarakat yang meningkat menjadi 90\%. Peningkatan ini dapat disebabkan oleh keberhasilan program penyuluhan oleh Tim Penggerak dan Kelompok PKK.

2. Tanggapan dan penilaian seluruh anggota Tim Penggerak dan Kelompok PKK terhadap kegiatan pembekalan soft-skill ini juga baik. Ini dapat dilihat dari rata-rata penilaian oleh seluruh anggota Tim Penggerak dan Kelompok PKK terhadap kegiatan pembekalan ini. Hasil Perhitungan rata-rata penilaian dengan menggunakan metode MOS menunjukan nilai 4.1067. Nilai MOS ini menunjukan bahwa kegiatan pembekalan soft-skill sesuai dengan kebutuhan dari seluruh anggota Tim Penggerak dan Kelompok PKK di Kelurahan Bulu Lor.

\section{SARAN}

Saran yang dapat disampaikan untuk perbaikan kegiatan pembekalan soft-skill lebih lanjut adalah :

1. Materi mengenai pemanfaatan teknologi internet perlu digali lebih jauh misalnya untuk membantu memasarkan ataupun mempublikasikan produk-produk maupun kegiatan/program di Kelurahan Bulu lor.

2. Perlu adanya pengembangan teknologi komputer di lingkungan Kelurahan Bulu Lor, misalnya penambahan peralatan unit komputer dan jaringan internet (WiFi). Hal ini akan berdampak pada kemudahan anggota Tim Penggerak dan Kelompok PKK dalam melaksanakan kegiatan administrasi dan pengkasesan jaringan internet.

\section{UCAPAN TERIMA KASIH}

Tim peneliti mengucapkan terima kasih kepada beberapa pihak sehingga kegiatan ini dapat berjalan dengan baik, yaitu

1. Universitas Dian Nuswantoro melalui program Pengabdian Masyarakat di Lembaga Penelitian dan Pengabdian Masyarakat (LPPM) yang telah memberikan dana untuk pelaksanan kegiatan ini. 
2. Pemerintah Kelurahan Bulu Lor yang telah memberikan ijin untuk pelaksanan Kegiatan Pengabdian Masyarakat.

3. Seluruh anggota Tim Penggerak dan Kelompok PKK di Kelurahan Bulu Lor yang telah bersedia menjadi peserta pelatihan dan objek pengabdian masyarakat.

[1] J. Glenn Brookshear, Edisi 7, 2004, Computer Science : Suatu Pengantar, Penerbit Erlangga. pp. $20-30$.

[2] Syarief, YA., 2013, Kompetensi Kewirausahaan Petani Jagung di Provinsi Lampung. Disertasi Program Pascasarjana UNS, Surakarta.

[3] Bahua, M. I., \& Limonu, M., 2013, Model pengembangan kompetensi penyuluh pertanian di Provinsi Gorontalo. Universitas Negeri Gorontalo

[4] Daisy, K dan Azura, A.E., 2011, A Preliminary Study of Top SMEs in Malaysia: Key Success Factor vs Government Support Program. Journal of Global Business and Economics. Volume 2, Number 1, pp. 48-58.

[5] Hazlina, N., Wilson, C., dan Kummerow, L. 2011, A Cross-Cultural Insight into the Competency-Mix of SME Entrepreneurs in Australia and Malaysia. International Journal of Business and Management Science, Vol. 4, No. 1,pp 33-50.

[6] Aripin, Surya Sumpeno, Mochamad Hariadi, Arry Maulana Syarif, 2017, Development of Indonesian Text-to-Audiovisual Synthesis System Using Syllable Concatenation Approach to Support Indonesian Learning. International Journal: Emerging Technologies in Learning (iJET), vol. 12 no. 02. 